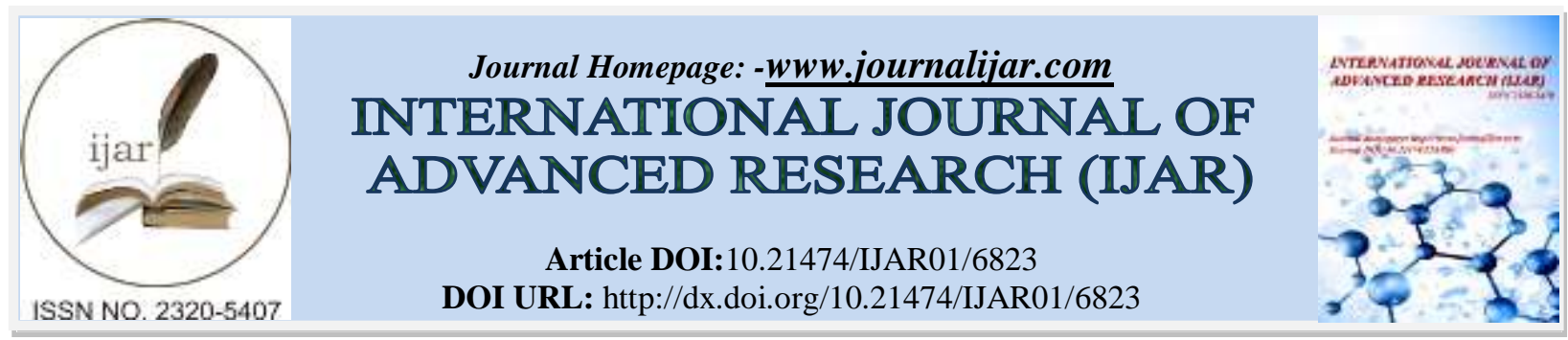

RESEARCH ARTICLE

\title{
FACTORS INFLUENCING HIGH PREVALENCE OF FRESH STILL BIRTHS IN MBAGATHI COUNTY HOSPITAL, NAIROBI - KENYA.
}

\begin{abstract}
Abednego Ongeso ${ }^{1}$, Magdalene Lukorito ${ }^{2}$ and Jane Kabo ${ }^{3}$.
1. $\mathrm{PhD}$ in Community Health and Development -Reproductive Health (Great Lakes University of Kisumu, Kenya), MSc.N - Maternal and Neonatal Health (Moi University, Kenya), BSc.N (Moi University, Kenya). Lecturer, School of Nursing Sciences University of Nairobi, Box 19676 - 00200 Nairobi. Tel +254720775815.

2. BSc.N (UoN, Kenya). Staff nurse, Gertrude's Children Hospital, Box 42325 - 00100 Nairobi. Tel $+254722670053$

3. PhD candidate UNISA (S. Africa), MSc.N - Midwifery \& Obstetric Nursing (UoN, Kenya), BSc.N (Aga Khan University, Kenya). Senior instructor, Aga Khan University, Box 39340-00623 Nairobi. Tel +254722591518
\end{abstract}

\section{Manuscript Info}

Manuscript History

Received: 02 February 2018

Final Accepted: 04 March 2018

Published: April 2018

Keywords:-

Fresh still births, developing countries, risk factors, perinatal mortality.

\section{Abstract}

Background: The annual global burden of stillbirths is approximately 2.6 million, 98\% of which occur in Sub Saharan Africa. In 2016, approximately 24 still births per month occurred in Mbagathi County Hospital (MCH) representing a 33.3\% increase from 2015. A third of these were Fresh Still Births (FSBs).

Objectives: To establish factors influencing increase in FSB among women delivering at $\mathrm{MCH}$.

Methodology: The study was conducted at MCH postnatal ward. A descriptive cross sectional study design was employed. Forty three respondents with FSBs were consecutively sampled. Clearance to conduct the study was sought from Ethics Review Committee, MCH and respondents. Researcher administered questionnaires were used for data collection over two months. Descriptive data involved calculation of measures of central tendency. Findings were presented in tables, graphs and narrative.

Results: A majority of the respondents were less than 20 years old, had low education level and were unemployed. Also the biggest proportion had preterm deliveries; prolonged premature rupture of membranes, had medical conditions and attended antenatal care less than four times. Most of the FSBs had complications and were delivered preterm. The facility had inadequate staffing, lacked prompt triaging equipment, and rarely used partograph to monitor labor.

Conclusion: Maternal, fetal and hospital related factors influenced high prevalence of FSB.

Recommendations: Improve uptake of focused antenatal care among women. Need for girl child empowerment in line with Sustainable Development Goal 5. Improve midwife to patient ratio, develop protocol regarding triaging and labor monitoring. Avail hospital equipment for proper maternity care.

Copy Right, IJAR, 2018,. All rights reserved. 


\section{Introduction:-}

\section{Study background:-}

Globally, 2.6 million still births occur annually, with more than 7, 178 deaths a day. The majority of these deaths occur in developing countries such as sub Saharan Africa and Asia. Ninety-eight percent occur in low and middle income countries and about half of all stillbirths occur in the intrapartum period hence are fresh still births (WHO, 2015). Almost half of all the fresh still births occur when the woman is in labor and under unskilled birth attendants. (Lawn, Blencowe, Pattinson, Cousens, Kumar, Ibiebele, 2016)

According to world health organization (WHO), still birth is a baby born dead at 28 weeks of gestation or more, with a birth weight of $\geq 1000 \mathrm{~g}$, or a body length of $\geq 35 \mathrm{~cm}$. The still births may be fresh (death a few hours before delivery) or macerated (death which occurred many days intra utero before birth) (WHO, 2015). Majority of these deaths are very devastating to both parents and have been documented to cause a lot of anxiety, long term depression, post-traumatic stress disorder and stigmatization especially among the women (Msemo, Massawe, Mmbando, Rusibamayila, Manji, Kidanto, \& Perlman, 2013)

Sub-Saharan Africa bears the greatest burden in terms of the number of cases of still births contributing about $60 \%$ of the global perinatal mortality (WHO, 2015). Majority of these deaths in Sub Saharan Africa are due to high proportion of home deliveries, poor antenatal clinic attendance, inaccessible healthcare facilities poverty and inadequate healthcare personnel especially midwives (Aminu, Unkels, Mdegela, Utz, Adaji, \& den Broek, 2014).

In Kenya, the number of still births continues to be very high compared to other countries worldwide, where Kenya is ranked at position 42 among 193 countries with the highest rates of still births globally (WHO, 2009). According to International still birth alliance Save the Children report on still birth, the total number of births in Kenya per year is $1,564,2010$, the total number of still births per year is estimated at 34,130 , therefore still births per 1,000 births in Kenya stands at 21.8 which is one of the highest in the world compared to world average which is 12.5 still births per 1,000 births.

Many studies suggest that majority of these deaths could easily be prevented if their causes and contributing factors which are region specific are known.

\section{Statement of the Problem:-}

Still birth rate is high in many developed and developing countries across the globe, however, majority of these deaths continue to occur in large proportions especially in developing countries within Sub Saharan Africa including Kenya (WHO, 2017). Such deaths could easily be prevented with proper Focused Antenatal Care and skilled birth attendance (Flenady, Koopmans, Middleton,Frøen, Smith, Gibbons, K.,\&Fretts, 2011)

In Mbagathi County Hospital, the number of stillbirths increased over the last few years. In the year 2016, approximately 24 still births were recorded per month. This was found to be a $33.3 \%$ increase compared to the previous year - 2015 (Mbagathi reproductive health report 2015/2016). Further according to quarterly infant mortality audit 2015/2016, more than one third of the still births in the hospital were Fresh still births. This trend continued to be witnessed in the first quarter of 2017.

\section{Purpose of the Study:-}

This study therefore sought to investigate the factors influencing high prevalence of Fresh still births in Mbagathi County Hospital.

\section{Justification:-}

Despite the large number of stillbirths worldwide, the causes of stillbirths in developing countries received very little research, programmatic or policy attention (Di Mario \& Lincentto, 2007). The rate of still birth in developing countries continues to be tenfold greater or more than in developed countries increasing infant mortality, yet these deaths are easily preventable (WHO, 2015).

This study was therefore necessary to determine prevalence and risk factors contributing to increased incidences of still birth among women delivering at Mbagathi County Hospital. The findings of this study would be critical in 
developing recommendations on evidenced based ways of preventing still births among pregnant women giving birth in Mbagathi County Hospital and the country at large. Further the study is important as the findings would be useful in developing training guidelines and policy review for healthcare workers and women of reproductive geared towards prevention of still births.

\section{Main Objective:-}

To determine the prevalence and risk factors for stillbirth among pregnant women delivering at Mbagathi County Hospital

\section{Specific Objectives:-}

1. To establish maternal factors contributing to stillbirth among pregnant women at Mbagathi County Hospital

2. To identify fetal factors contributing to stillbirths among pregnant women at Mbagathi County Hospital.

3. To determine hospital related factors contributing to still birth among pregnant women in Mbagathi County Hospital

\section{Research Questions:-}

1. What are the maternal factors contributing to still birth among pregnant women at Mbagathi County hospital?

2. What are the fetal factors contributing to still birth among pregnant women delivering at Mbagathi county Hospital?

3. What are the hospital related factors contributing to still birth among pregnant women delivering at Mbagathi County Hospital?

\section{Literature Review:- \\ Maternal Related Factors to Fresh Still Birth:-}

In a study by Feresu, Harlow, Welch, \& Gillespie, (2005) on incidences of still births and perinatal mortality and their associated factors among pregnant women established that fresh still births were associated with women with low or no antenatal clinic visits and those who had unskilled delivery. In a similar study by Turnbull, Lembalemba, Brad Guffey, Bolton,Moore, Mubiana, Mbewe, Chintu,\& Chi, (2011) on causes of stillbirth, neonatal deaths and early childhood deaths in rural Zambia, it was found that, women with poor educational standards, and those of poor economic status were experiencing more incidences of generally still births both macerated and fresh still birth in relation to more educated and high economic status counterparts. In the same study it was found that women of low education status and those of poor economic status are associated with lack of antenatal care visits which could otherwise help in early detection of possible or impending still births.

Flenady et al (2011) in a study on major risk factors for still births in high income countries, found that fresh still births were common among mothers living in urban area, and women who present late for prenatal care and those who had a gestational age of less than 28 weeks and did not receive prenatal care at all. Further, in the study it was found that fresh still births were also common among primigravidas compared to multiparous women especially those who did not receive adequate care due to illegality of the pregnancy. In a similar study by Gordon, RaynesGreenow, McGeechan, Morris, and Jeffery (2013) on maternal and fetal risk factors for still birth established that maternal medical conditions during pregnancy was linked to still births both macerated and fresh still birth. Such conditions were pre- eclampisa, diabetes, antepartum hemorrhage, and placenta abruption and severe anemia. Others were Road Traffic Accidents, depression, malnutrition and stress related factors. Lawn et al., (2016) risk factors to still birth, found that maternal obesity (body mass index greater than 30 , smoking, pre-existing diabetes, and history of mental health problems, antepartum hemorrhage, fetal growth retardation were potential risk to still births.

In a study by Carolan and Frankowska (2011) on advanced maternal age and advanced perinatal outcome, maternal overweight and obesity were high ranking maternal risk factors to still births. Further the study established that advanced maternal age (>35 years) and maternal smoking were associated to still births. Other maternal conditions such as pre-eclampisa, obstructed labour and premature rupture of membranes in addition to underlying maternal medical conditions were associated with fresh still births. Pre-existing diabetes and hypertension remained important contributors to stillbirth in such countries.

According to still birth collaborative research network writing group (2011), Social factors affecting pregnant mothers during pregnancy had significant association with still births. Mothers who were experiencing social deprivation, unemployed or their partners lacking reliable source of outcomes were found to have high incidences of 
still births both fresh and macerated births. Further, Lawn et al., (2011) established that Pregnancies in which the parents were blood relations were not at a significantly increased risk. In addition, Obesity (body mass index $\geq 30$ ), active as well as passive smoking, lack of antenatal folic acid, and booking after 13 weeks were all associated with an increased risk of stillbirth. The study further established that a history of mental health problems, diabetes, and stillbirth increased the risk. Pre-eclampisa and antepartum hemorrhage were strongly associated with fresh still birth, whereas gestational diabetes mostly associated with macerated still births.

\section{Institutional Related Factors:-}

Healthcare institutions were found to play an important role in determining the quality of pregnancy outcome especially maternal and neonatal wellbeing during and after delivery (WHO, 2015). Studies have shown that fresh stillbirths and early neonatal deaths or mortality (ENNM) may suggest problems with the care available during labor and delivery at any given healthcare facility (Ersdal et al., 2013). According to Musafili et al., (2013) numerous hospital based factors are a major contributor to fresh still birth in many countries across the globe. For instance many facilities in many countries are always understaffed, hence have inability to accurately monitor labor progress and conduct quality deliveries (Lee et al., 2011). Similarly, in a study by Flenadi et al., (2011), health facility inaccessibility in terms of distance and costs has a great impact on the delivery outcomes. The study showed that half of pregnant women delivered at home for reasons that included logistical difficulties in accessing clinical care, transportation costs and a lack of adequate health education from healthcare facilities. In such cases many fresh still births occurred due to inaccessibility of quality labor monitoring and delivery under unqualified healthcare providers. Lawn et al., (2011) established that, many still births occured due to poor monitoring of labor in many health facilities that had been occasioned by shortage of staff hence high workload. The study further found that, the high number of pregnant women visiting the facility with acute shortage of healthcare workers was a major contributing factor.

Aminu et al., (2014) in a study to assess causes of and factors associated with stillbirths in low and middle income countries established that poor use of partograph to monitor labor, lack of theatre facilities and shortage of staff were institutional related factors that contributed to fresh still births among pregnant women. In a similar study, Spong et al, (2011), established that, inaccessibility to the health facility, overcrowding, long waiting hours and high cost of delivery services were associated with increased incidences of fresh still births in many facilities. In addition, poor triaging of mothers, especially those who had history of still births, prolonged labor or underlying conditions such as pre- eclampsia and intrauterine growth retardation was another hospital related factor that also contributed to Fresh Still birth occurrence. Turnbull et al. (2011) showed that a large proportion of stillbirths in high-income countries were attributable to risk factors that were fully or partly avoidable in many healthcare facilities. Delay in decision making on whether mother is to deliver normally or through caesarian section was a major contributor to still births. The study recommended immediate Caesarian section to any mother with signs of fetal distress to save the life of the baby. According to Hogue, and Silver, (2011) culturally appropriate preconception care and quality antenatal care that is accessible to all women had the potential to reduce stillbirth rates in high-income countries. Implementation of national perinatal mortality audit program in hospitals and other healthcare facilities aimed at improving the quality of care could substantially reduce stillbirths.

\section{Fetal Factors Contributing To Fresh Still Births:-}

Women from disadvantaged populations in many countries across the world continue to have higher stillbirth rates than those living without such disadvantages; fetal conditions have been associated with still births both fresh and macerated among many pregnant women (Aminu et al., 2014). Studies have shown that, many treatable maternal factors which have an effect on growth and well-being of the baby have been shown to contribute to still birth if no prompt intervention is made (Flenady et al 2011;Spong et al, 2011). Further risk of still births in many countries is associated with treatable and complications of pregnancy which have devastating effects on the baby.

A study conducted by Lawn et al., (2016) on risk factors to still births found that, small for gestational age, and twin pregnancy were highly associated with still births especially in cases where there was no adequate monitoring of labor, and inadequate facilities and staff in labor wards. Frøen, Friberg, Lawn, Bhutta, Pattinson, Allanson and Kinney (2016) in their study, reported that prematurity is a major risk factor in fresh still birth. Majority of fresh birth cases were premature deliveries within the facility. Further the study also established that those extremes of birth weight increased the risk for stillbirth. However, there was no association between still births and the baby's gender. In a similar study by Heazell et al., (2016) it was found that still birth was common among preterm and low birth weight babies. The study showed that still births were common in poor maternal nutritional status, absence of 
antenatal care, and complications during labor. According to Wallis (2013) in a study on maternal and fetal factors associated with still births established that fetal growth restriction (FGR), twin pregnancies, and premature births were associated with Fresh Still Births.

Kidanto et al., (2015), established that the Risk for stillbirth increased in situations where there was fetal distress during delivery, such as uterine rupture placental abruption, cord prolapse and prematurity. Similarly, Gardosi et al., 2012) found out that fetal growth restrictions, low birth weight, prematurity, and fetal distress due to premature rupture of membranes were highly associated with still births. In the same study, it was established that fetal growth restriction was eight times highly associated with still births. This was supported by the fact that growth restrictions delays birth thereby resulting in death prior to delivery.

\section{Methodology:- \\ Study Design}

This was an institutional based descriptive cross-sectional study design containing quantitative methods which was conducted to assess the prevalence and risk factors to stillbirth among pregnant women delivering at Mbagathi County Hospital.

\section{Study Site:-}

The study was carried out at the post natal wards in Mbagathi County Hospital. The hospital is situated in Kenyatta Golf Course, Daggoretti Division of Nairobi County. The hospital has several departments which include outpatient, Laboratory, Pharmacy, Medical and Surgical wards, Pediatric ward, Gynecological ward, TB department, Eye and dental clinic, Maternity ward, Maternal and Child Health Clinic and comprehensive care unit.

The reproductive health department (Labor and post natal wards) was selected purposively for carrying out the study because all the mothers after delivery were discharged through. The post natal wards are fully manned by qualified, competent, experienced human resource for health of all cadres consisting of several Medical Officers and midwives who form the bulk of primary health providers in all facilities.

\section{Study Population:-}

The study population comprised of all mothers who had fresh still births at the facility and on average 24 mothers had still births per month at Mbagathi County Hospital at the time of the study.

\section{Sampling:-}

Sample size calculation:-

The sample size was determined using Cochran's formula, (Cochran 1977) A Sample size of 42 mothers was recruited for the study.

\section{Sampling Method:-}

Consecutive sampling method was used to select the study respondents. Any mother who had a fresh still birth at the time of the study and was willing to participate in the study was recruited.

\section{Data Collection Tool:-}

Data was collected using researcher administered structured questionnaires. The questionnaires had 4 parts, i.e. demographic characteristics, maternal factors, fetal factors, and hospital related factors contributing to fresh still births.

\section{Pretesting of the Study Tool:-}

A pre-test of the tool was done in Pumwani Maternity Hospital. This was to determine the validity and reliability of the tool. Pretesting also helped the researcher to modify the study tool to be able to capture all the information that helped answer the research questions and met the study objective. Ten percent $(10 \%)$ of the sample size of 42 , which was approximately 5 mothers were recruited for pretesting.

\section{Data Management:-}

All the study respondents were assigned a respondent identification number (RID). All data entered into the study databases was identified and only associated with a RID in password protected files. A double entry system for the 
data was maintained. All paper research records were secured in a lockable filling cabinet. Data entry, cleaning and validation was performed in order to achieve a clean data. Soft copies of the data collected were password protected

\section{Statistical Analysis:-}

Data entry and statistical analysis was performed using Statistical Package for Social Sciences (SPSS) version 23. Descriptive statistics were analyzed where measures of central tendency like mean mode and median was calculated. The results were presented using tables, bar graphs and pie charts.

\section{Ethical Considerations:-}

Ethical Principles:-

The three ethical principles; Beneficence, Autonomy and Justice were upheld. This research was carried out in accordance with the basic principles defined in Guidance for Good Clinical Practice and the Principles enunciated in the Declaration of Helsinki (Edinburg, October 2000).

\section{Dissemination of findings:-}

Research findings were disseminated to the hospital management through a report. The findings were also presented in symposia, conferences and publication in peer reviewed journals.

\section{Results:-}

\section{Maternal factors:-}

\section{Demographic Profile for the Study Respondents:-}

Of the 40 respondents who participated in the study, majority $22(55.0 \%)$, were aged below 20 years. Similarly, more than two thirds 27 (68.2\%), were married.

Regarding level of education, majority $23(57.5 \%)$ had primary education as their highest level of education, with 25 $(62.5 \%)$, being unemployed as shown in Table 1 below;

Table 1:-Demographic characteristics of the respondents in $\mathrm{MCH}(\mathrm{n}=40)$

\begin{tabular}{|l|c|c|}
\hline Characteristics & Frequency (n=40) & Percentages (\%) \\
\hline Age in years & & \\
Below 20 & 22 & $\mathbf{5 5 . 0}$ \\
$21-30$ & 10 & $\mathbf{2 5 . 0}$ \\
$31-40$ & 03 & $\mathbf{0 7 . 5}$ \\
Above 41 & 05 & $\mathbf{1 2 . 5}$ \\
\hline Marital status & & $\mathbf{2 7 . 5}$ \\
Single & 11 & $\mathbf{6 8 . 2}$ \\
Married & 27 & $\mathbf{0 2 . 5}$ \\
Widowed & 01 & $\mathbf{0 2 . 5}$ \\
Divorced & 01 & \\
\hline Level of education & & $\mathbf{5 7 . 5}$ \\
Primary & 23 & $\mathbf{2 0 . 0}$ \\
Secondary & 08 & $\mathbf{1 5 . 0}$ \\
College & 06 & $\mathbf{0 7 . 5}$ \\
University & 03 & $\mathbf{0 0 . 0}$ \\
Never attended & 00 & $\mathbf{1 0 . 0}$ \\
\hline Occupation & & $\mathbf{0 7 . 5}$ \\
Employed & 04 & $\mathbf{2 0 . 0}$ \\
Self employed & 03 & $\mathbf{6 2 . 5}$ \\
Casual labourer & 08 & \\
Unemployed & 25 & \\
\hline
\end{tabular}

\section{Gestational age at birth:-}

Majority of the respondents 29 (72.5\%), had a preterm pregnancy, followed by 8 (20.0\%) who had a term pregnancy at delivery as shown in figure 1 below; 


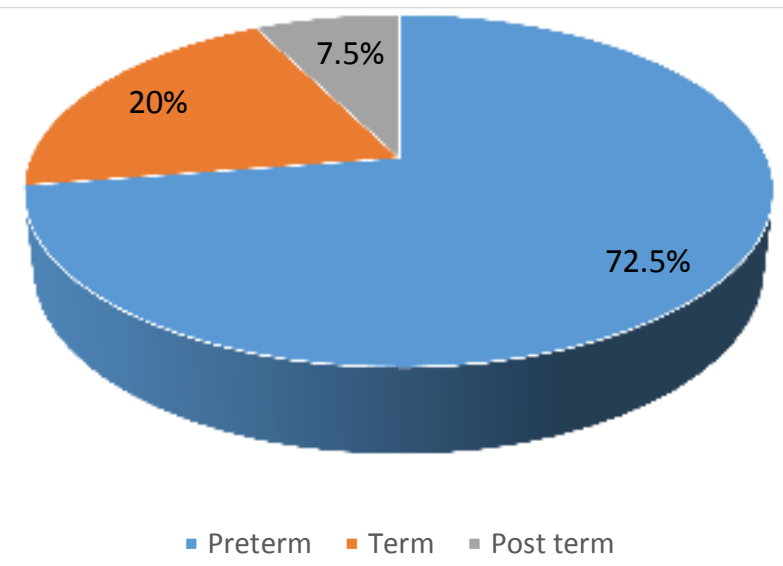

Fig 1:-Gestational age at birth among respondents in $\mathrm{MCH}(\mathrm{n}=40)$

Proportion of respondents whose membranes ruptured before labor:-

Majority $31(77.5 \%)$ had ruptured membranes before labor pains, while $9(22.5 \%)$ had their membranes intact before the start of labor.

\section{Duration of Ruptured Membranes before Labor:-}

Of all the respondents who had ruptured membranes before labor, majority $24(77.5 \%)$ of them had their membranes ruptured more than 18 hours before labor while 7 (22.5\%) had membranes ruptured less than 18 hours before labor.

\section{Medical conditions during pregnancy:-}

Respondents were asked if they had any medical conditions during pregnancy, majority 27 (67.5\%), indicated that they indeed had the conditions while $13(22.5 \%)$ did not.

\section{The medical conditions that respondents had during pregnancy:-}

Of all the respondents who had medical conditions during pregnancy majority 16 (59.3\%) had placenta Previa and abruptio, followed by severe pre-eclampsia 4 (14.8\%) as shown in Fig 2 below; 


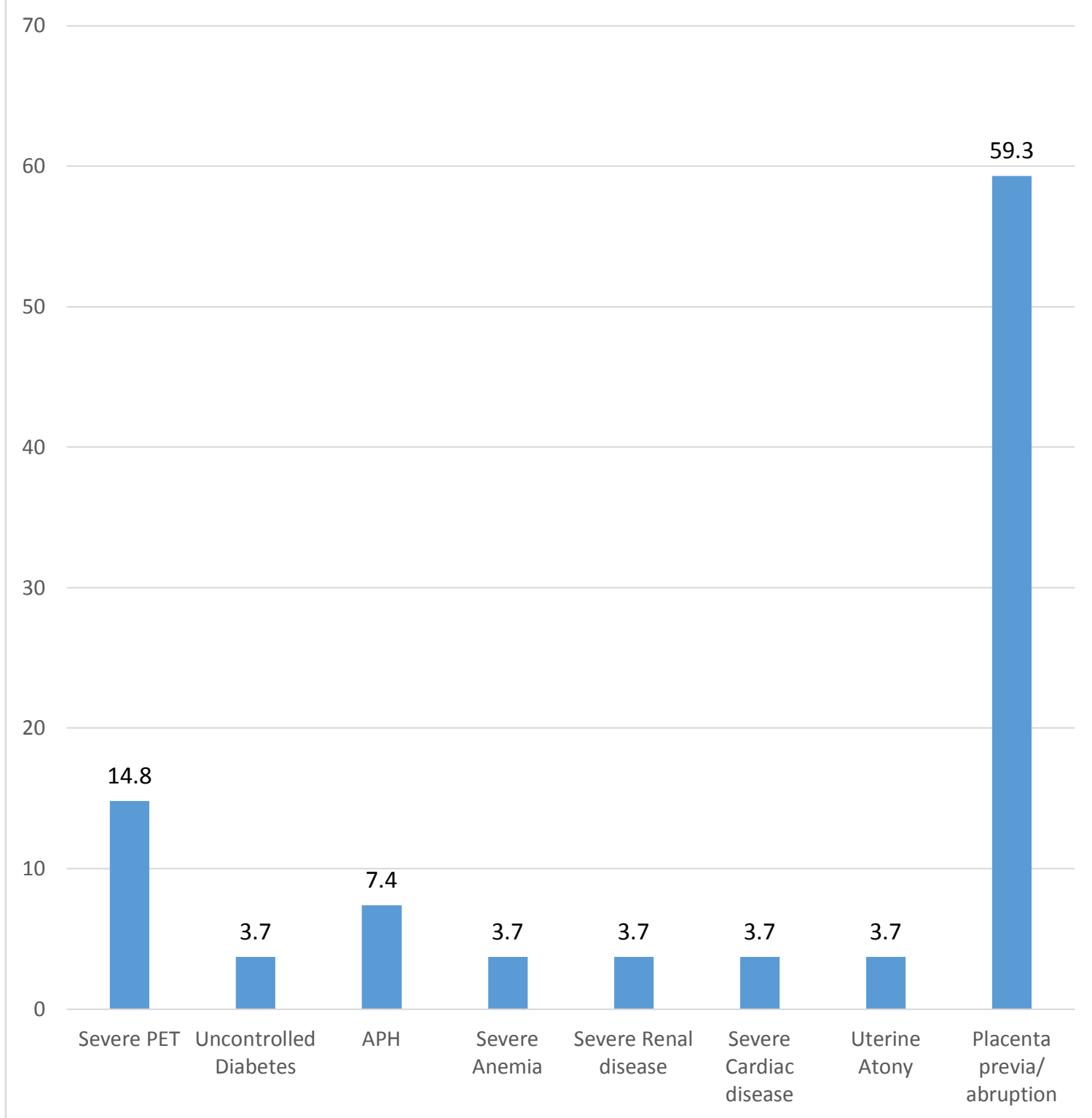

Fig 2:-Common medical conditions among respondents during pregnancy $(\mathrm{n}=27)$

Other predisposing risk factors:-

Table 2 illustrates various maternal factors that contribute to fresh still births. Majority $22(55.0 \%)$ of the respondents had a history of previous still birth. Regarding Antenatal Clinic (AANC) attendance, a majority 25 (62.5\%), had not made any antenatal clinic visits. Among the respondents who made ANC visits $(\mathrm{n}=15)$ two thirds had made less than 4 visits. Finally, majority 28 (70.0\%), reported that they took alcohol though didn't smoke.

Table 2:-A Maternal Risk factors that contribute to FSB among women delivering in MCH

\begin{tabular}{|l|c|c|}
\hline Characteristics & Frequency $(\mathbf{n = 4 0})$ & Percentages (\%) \\
\hline History of still birth & $\mathbf{n = 4 0}$ & \\
Yes & 18 & $\mathbf{4 5 . 0}$ \\
No & 22 & $\mathbf{5 5 . 0}$ \\
\hline ANC attendance & $\mathbf{n = 4 0}$ & \\
Yes & 15 & $\mathbf{3 7 . 7}$ \\
No & 25 & $\mathbf{6 2 . 5}$ \\
\hline Number of ANC visits & $\mathbf{n = 1 5}$ & \\
\hline
\end{tabular}




\begin{tabular}{|l|c|c|}
\hline Less than 4 & 10 & $\mathbf{6 6 . 7}$ \\
Four visits & 04 & $\mathbf{2 2 . 7}$ \\
More than Four & 01 & $\mathbf{0 6 . 6}$ \\
\hline Smoking and Taking alcohol & $\mathbf{n = 4 0}$ & $\mathbf{0 5 . 0}$ \\
Yes & 02 & $\mathbf{1 0 . 0}$ \\
I only smoke & 04 & $\mathbf{7 0 . 0}$ \\
I only take alcohol & 28 & $\mathbf{1 5 . 0}$ \\
No & 06 & \\
\hline
\end{tabular}

\section{Fetal Related Factors:-}

Baby's Gestation in Weeks:-

Majority of the respondents 29 (72.5\%), had a gestation below 37 weeks as shown in the figure 3 below;

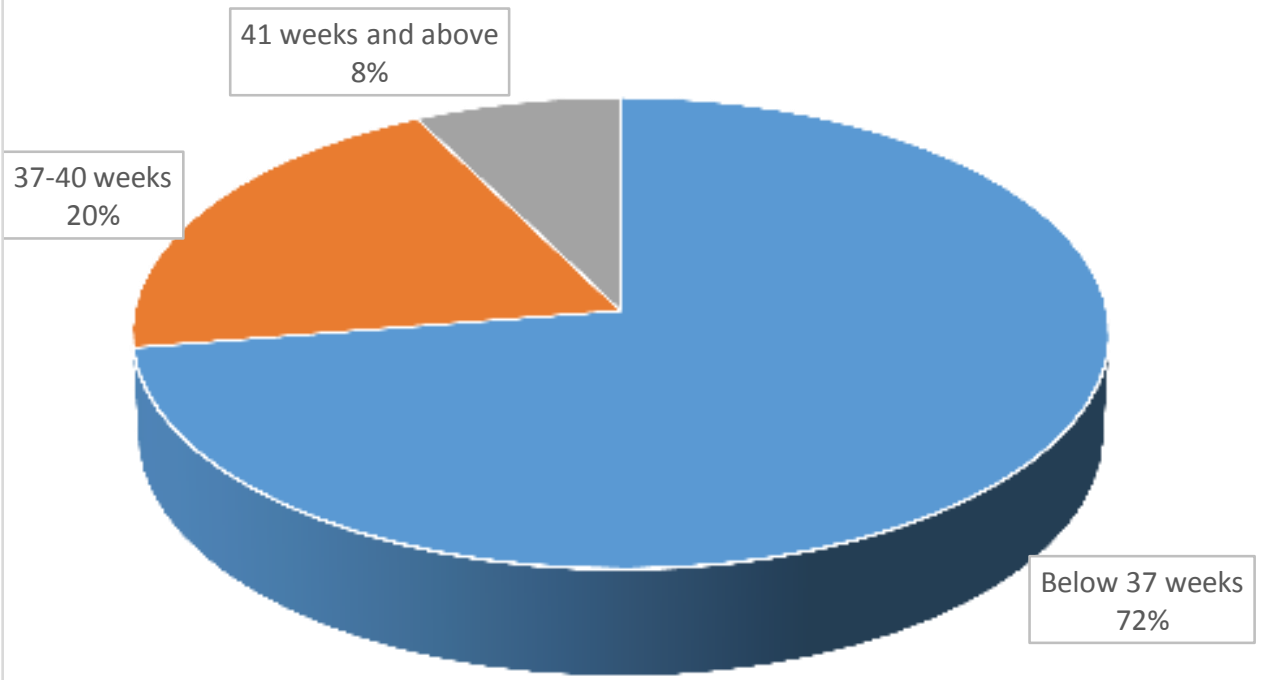

- Below 37 weeks - 37-40 weeks 41 weeks and above

Fig 3:-Fetal gestation in weeks among FSBs at MCH $(n=40)$

Presence of Fetal Complication during Pregnancy:-

Majority $33(82.5 \%)$ of the babies had fetal complications during pregnancy while 7 (17.5\%) had normal babies. 


\section{Fetal complications during pregnancy:-}

Among the 33 fetuses who had complications leading to their demise, majority of them 18 (54.5\%) had a potential for fetal distress secondary to PROM followed by 7 (21.7\%) who had intrauterine growth retardation as shown in the figure 4 below;

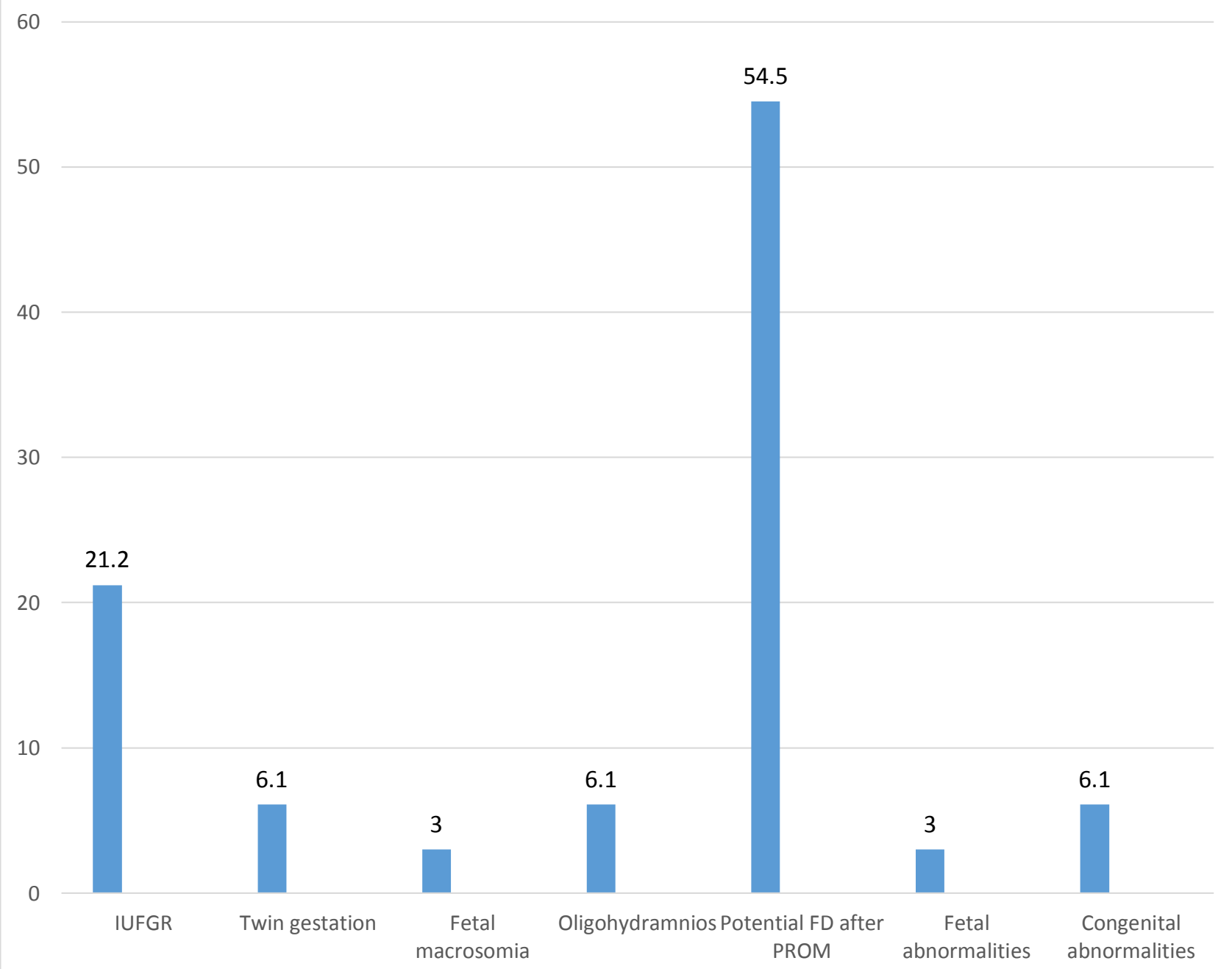

Fig 4:-Fetal complications during pregnancy among FSBs in $\mathrm{MCH}(\mathrm{n}=33)$

\section{Institutional Related Factors:-}

The following institutional factors were checked on daily basis during the data collection period that lasted 10 days. A check list was used and assessment was done daily during the data collection. The findings were as shown in table 3 below. There was a staff shortage as evidenced by very low midwife to patient ratio. The mothers were not triaged in $60 \%$ of the cases. Similarly, $80 \%$ of the days, partograph was not used to monitor labor. Further, there were no cardiac monitors and Blood Pressure (BP) machines were not adequate in the facility. However, there were availability of fetoscope, resuscitaires and operating theatres. 
Table 3:-Institutional related factors contributing to FSBs at MCH

\begin{tabular}{|c|c|c|c|c|}
\hline \multirow[t]{2}{*}{ Institutional Factors } & \multicolumn{2}{|c|}{ Yes } & \multicolumn{2}{|c|}{ No } \\
\hline & $\mathbf{f}$ & $\%$ & $\mathbf{f}$ & $\%$ \\
\hline Adequate staff (Check midwife to patient ratio) & 3 & 30.0 & 7 & 70.0 \\
\hline Triaging of pregnant mothers as they come & 4 & 40.0 & 6 & 60.0 \\
\hline Use of partograph to monitor mothers in labor & 2 & 20.0 & 8 & 80.0 \\
\hline \multicolumn{5}{|l|}{ Availability of equipment } \\
\hline \begin{tabular}{l|l} 
BP machine \\
\cline { 2 - 2 }
\end{tabular} & 5 & 50.0 & 5 & 50.0 \\
\hline Cardiac monitors & 0 & 00.0 & 10 & 100 \\
\hline Fetoscope & 10 & 100 & 0 & 00.0 \\
\hline Resuscitation drugs & 7 & 70.0 & 3 & 30.0 \\
\hline Resuscitaire & 10 & 100 & 0 & 00.0 \\
\hline Glucometer & 6 & 60.0 & 4 & 40.0 \\
\hline Availability of functional operating theatres for emergencies & 7 & 70.0 & 3 & 30.0 \\
\hline
\end{tabular}

\section{Discussion:-}

\section{Maternal factors:-}

Study findings revealed that majority of the mothers who had fresh still birth, were young, aged below 20 years, had low literacy level and of low socio-economic status. These findings were in agreement with a study by Turnbull et al., (2011) who found that high incidence of fresh still birth was common among young women of low education status and poor economic backgrounds. The study findings were also in agreement with a study by Flenady et al (2011) who found that fresh still births were also common among young teenage girls who were primigravidas compared to older multiparous women especially those who did not receive adequate care due to illegality of the pregnancy.

In the study, it was established that majority of the mothers who had fresh still births had a preterm pregnancies and similar proportion had their membranes ruptured 18 hours prior to labor. Findings of which concurred with a study by Gordon et al., (2013) which established that fresh still births were common among women with prolonged duration of premature rupture of membranes especially in preterm deliveries.

Further, in this study, it was established that two third of the mothers who had still births had medical conditions during pregnancy. The common medical condition was placenta previa and placenta abruptio, followed by severe pre- eclampsia. Others were ante partum hemorrhages, uterine atony, and severe anemia. The findings were in agreement with a study by Lawn et al., (2016) who found that mothers who had certain medical conditions such as placenta previa, antepartum hemorrhage, severe pre- eclampsia and diabetes were likely to have fresh still birth if they were not properly managed or controlled early. The findings were also in agreement with a study by Carolan and Frankowaska (2011) who also found that maternal conditions such as pre-eclampisa, obstructed labor and premature rupture of membranes in addition to underlying maternal medical conditions were associated with fresh still births. Pre-existing diabetes and hypertension remained important contributors to stillbirth in such countries.In this study, it was also found that majority (55\%) of the mothers had history of previous still birth either fresh or macerated, findings of which was in agreement with those of Carolan and Frankowaska (2011), who established that previous fresh still births was a predictor of women who were likely to have fresh still births even in future pregnancies and as such, special attention should given to such women.

In so far as ANC attendance is concerned, majority of the respondents had not attended antenatal clinic at all with only slightly over one third attending majority of who had attended less than 4 visits. Further, $85 \%$ of them were either smoking or taking alcohol or both. This indicated that fresh still births were common among women with no or minimal ANC visits findings of which were similar to those by a study by Turn bull et al., (2011) which found that fresh still births were common among women who lack of antenatal care visits which could otherwise help in early detection of possible or impending still births as well as women who seek health care at the last minute in their pregnancy, such as during labor.

\section{Fetal Related Factors:-}

The study established that majority of the babies had a gestation of less than 37 weeks and hence were born prematurely. This showed that prematurity was associated with Fresh Still Births. These findings were in agreement 
with a study by Line et al., (2016) who found that risk factors to still births included small for gestational age or children who were born preterm. The findings were also similar to a study by Froen et al., (2016) who established that prematurity was a major contributing factor to fresh still births and that majority of fresh still births were premature deliveries.

Further, in this study, it was also found that, more than three quarters of the fetuses had complications prior to birth. The common complications were mainly potential fetal distress following premature rupture of membranes and intrauterine fetal growth retardation. This demonstrated that fetal complications during pregnancies and fetal distress during labor were associated with fresh still births in cases where mothers were not given proper care. Findings of the study were in agreement with a study by Kidanto et al., (2015) who established that fresh still birth were common among babies who had fetal complications such as intrauterine fetal growth retardation, fetal distress due to premature rupture of membranes and congenital abnormalities. Findings were also similar to a study by Gardosi et al., (2012) who found that fetal growth restrictions, low birth weight, prematurity, and fetal distress due to premature rupture of membranes were highly associated with still births. In the same study, it was established that fetal growth restriction was eight times highly associated with still births. This was mainly found to be likely because the baby is often not delivered immediately, either due to inappropriate delays or because of concerns about neonatal immaturity.

\section{Institutional related factors:-}

The study found that there was low midwife to patient ratio hence the members of staff were not adequate to give quality midwifery care to the mothers. In addition, triaging of patients was not adequately done, which was likely to contribute to emergency cases being missed hence increased number of still births. Further, there was low utilization of partograph in monitoring of the pregnant women in labor. Majority of the equipments necessary in maternity were available, however there were no cardiac monitors, the Blood Pressure machines. The study therefore showed that, the facility lacked adequate staff, had low utilization of partograph, inadequate triaging of patients and lack of some necessary equipment for monitoring of very sick patients. The findings were similar to a study by Ersdal et al., (2013) who found out that fresh stillbirths were associated with inadequate care during labor due to lack of adequate members of staff and at delivery at any given healthcare facility lacking the necessary equipment. The findings were also in agreement with a study by Musafili et al., (2013) who found that understaffing, lack of triaging, inability to accurately monitor labor using partograph, lack of facilities and equipments were highly associated with poor delivery outcomes such as fresh still birth or fetal complications at birth such as severe birth asphyxia.

\section{Conclusions:-}

Based on the study findings and discussion above, the followings conclusions were drawn

1. Majority of the mothers with fresh still birth were young aged below 20 years, were of low socio-economic status and did not or made less than four ANC visits. They also had, previous history of still birth, had various medical conditions during pregnancy such as placenta previa/ abruption, APH and prolonged premature rupture of membranes before labor.

2. Majority of the babies were born prematurely (gestation less than 37 weeks), had fetal complications or congenital malformations in utero, and or developed severe fetal distress during labor.

3. Institutional factors associated with fresh still births were, low midwife to patient ratio, lack of utilization of partograph, lack of prompt triaging of pregnant mothers and inadequate or lack of vital equipments critical for monitoring mothers in labor.

\section{Recommendations:-}

Based on the above conclusion, the followings are the recommendations.

1. Improve uptake of safe motherhood through improving uptake of focused antenatal care among women of reproductive age and pregnant mothers. This can be done by targeting women of reproductive age in colleges, churches, and even during antenatal clinics.

2. Girl child empowerment to achieve gender equality in line with Sustainable Development Goal 5 will help reduce unwanted fetal deaths since they will be able to seek medical care when required.

3. Improve staffing; develop protocol regarding triaging and labor monitoring using partograph and monitor compliance.

4. The hospital to ensure availability and adequacy of equipments required for proper management of women in labor such as cardiac monitors 


\section{References:-}

1. Aminu, M., Unkels, R., Mdegela, M., Utz, B., Adaji, S., \& den Broek, N. (2014). Causes of and factors associated with stillbirth in low- and middle- income countries: a systematic literature review. BJOG: An International Journal of Obstetrics \&Gynaecology, 121(s4), 141-153.

2. Carolan, M., \&Frankowska, D. (2011). Advanced maternal age and adverse perinatal outcome: a review of the evidence. Midwifery, 27(6), 793-801.

3. Cochran, W. G. (1977). Sampling techniques (3rd ed.). New York: John Wiley \& Sons. Available at: https://gist.github.com/marcoscaceres/7137166 Accessed on 29th March, 2017

4. Ersdal, H. L., Vossius, C., Bayo, E., Mduma, E., Perlman, J., Lippert, A., \&Søreide, E. (2013). A one-day "Helping Babies Breathe" course improves simulated performance but not clinical management of neonates. Resuscitation, 84(10), 1422-1427.

5. Feresu, S. A., Harlow, S. D., Welch, K., \& Gillespie, B. W. (2005). Incidence of stillbirth and perinatal mortality and their associated factors among women delivering at Harare Maternity Hospital, Zimbabwe: a cross-sectional retrospective analysis. BMC pregnancy and childbirth, 5(1), 9.

6. Flenady, V., Koopmans, L., Middleton, P., Frøen, J. F., Smith, G. C., Gibbons, K.,\&Fretts, R. (2011). Major risk factors for stillbirth in high-income countries: a systematic review and meta-analysis. The Lancet, 377(9774), 1331-1340.

7. Frøen, J. F., Friberg, I. K., Lawn, J. E., Bhutta, Z. A., Pattinson, R. C., Allanson, E. R., ... \& Kinney, M. V. (2016). Stillbirths: progress and unfinished business. The Lancet, 387(10018), 574-586.

8. Gardosi, J., Madurasinghe, V., Williams, M., Malik, A., \& Francis, A. (2013). Maternal and fetal risk factors for stillbirth: population based study. Bmj, 346, f108.

9. Gold, K. J., Abdul-Mumin, A. R. S., Boggs, M. E., Opare-Addo, H. S., \& Lieberman, R. W. (2014). Assessment of "fresh" versus "macerated" as accurate markers of time since intrauterine fetal demise in lowincome countries. International Journal of Gynecology \& Obstetrics, 125(3), 223-227..

10. Gordon, A., Raynes-Greenow, C., McGeechan, K., Morris, J., \& Jeffery, H. (2013). Risk factors for antepartum stillbirth and the influence of maternal age in New South Wales Australia: a population based study. BMC pregnancy and childbirth, 13(1), 12.

11. Heazell, A. E., Siassakos, D., Blencowe, H., Burden, C., Bhutta, Z. A., Cacciatore, J., ...\&Mensah, O. K. (2016). Stillbirths: economic and psychosocial consequences. The Lancet, 387(10018), 604-616.

12. Hogue, C. J. R., \& Silver, R. M. (2011, August). Racial and ethnic disparities in United States: stillbirth rates: trends, risk factors, and research needs. In Seminars in Perinatology (Vol. 35, No. 4, pp. 221-233). WB Saunders.

13. Lawn, J. E., Blencowe, H., Pattinson, R., Cousens, S., Kumar, R., Ibiebele, I., \& Lancet's Stillbirths Series Steering Committee. (2011). Stillbirths: Where? When? Why? How to make the data count. The Lancet, 377(9775), 1448-1463.

14. Lawn, J. E., Blencowe, H., Waiswa, P., Amouzou, A., Mathers, C., Hogan, D.,\&Shiekh, S. (2016). Stillbirths: rates, risk factors, and acceleration towards 2030. The Lancet, 387(10018), 587-603.

15. Lee, A. C., Cousens, S., Wall, S. N., Niermeyer, S., Darmstadt, G. L., Carlo, W. A.,\& Lawn, J. E. (2011). Neonatal resuscitation and immediate newborn assessment and stimulation for the prevention of neonatal deaths: a systematic review, meta-analysis and Delphi estimation of mortality effect. BMC public health, 11(3), S12.

16. Msemo, G., Massawe, A., Mmbando, D., Rusibamayila, N., Manji, K., Kidanto, H. L.,\& Perlman, J. (2013). Newborn mortality and fresh stillbirth rates in Tanzania after helping babies breathe training. Pediatrics, 131(2), e353-e360.

17. Musafili, A., Essén, B., Baribwira, C., Rukundo, A., \&Persson, L. Å. (2013). Evaluating Helping Babies Breathe: training for healthcare workers at hospitals in Rwanda. Actapaediatrica, 102(1).

18. Spong, C. Y., Iams, J., Goldenberg, R., Hauck, F. R., \&Willinger, M. (2011). Disparities in perinatal medicine: preterm birth, stillbirth, and infant mortality. Obstetrics \& Gynecology, 117(4), 948-955.

19. Stillbirth Collaborative Research Network Writing Group. (2011). Causes of death among stillbirths. Jama, 306(22), 2459.

20. Turnbull, E., Lembalemba, M. K., Brad Guffey, M., Bolton- Moore, C., Mubiana- Mbewe, M., Chintu, N. ... \& Chi, B. H. (2011). Causes of stillbirth, neonatal death and early childhood death in rural Zambia by verbal autopsy assessments. Tropical Medicine \& International Health, 16(7), 894-901.

21. World Health Organization, Global udates 2018; Available at: http://www.who.int/maternal child_adolescent/epidemiology/stillbirth/en/ Accessed on $29^{\text {th }}$ March, 2018. 